\title{
INCIDENCE OF SEEDBORNE FUNGI OF SOYBEAN AND THEIR CONTROL USING MORINGA SEED EXTRACT
}

\author{
Fayinminu, A. O. \\ Department of Biological Sciences \\ Benue State University, Makurdi, Nigeria \\ Agbatar, B.L. \\ Department of Biological Sciences \\ Centre for Food Technology and Research \\ Benue State University, Makurdi, Nigeria
}

Abstract- Seed is a basic and vital input for increased agricultural productivity as vast majority of food crops are grown from seed. Although this increased in produce by seeds have always been challenged by abiotic and biotic factors in which the biotic factors plays a major role in reducing productivity. Therefore there is a need to improve on seed quality using treated methods that are non-toxic to humans in order to maximize productivity. Thus a study was carried out at the Department of Biological Sciences, Benue State University, Makurdi to investigate the incidence of seed borne fungi in soybean and their control using Moringa seed extract. A total of four markets namely; North Bank, Wadata, Railway and Wurukum were used for the collection of soybean samples. A total of Three hundred and sixty seeds (360) were collected across the four locations and were analyzed for seed borne infection. The blotter method of fungal detection and isolation was employed for the study. Moringa seed extract was prepared at different concentration of $10,20,30,40$ and $50 \% \mathrm{w} / \mathrm{v}$ for the in vitro control of fungi isolated. The result obtained showed the presence of three fungi found associated with soybean seeds which are; Aspergillus niger, Aspergillus flavus and Rhizopus stolonifer. There was no significant difference $(P>0.05)$ in percentage fungi occurrence across the location though North Bank market gave the highest value with $84.40 \%$ while Railway recorded the least with 58.90. Seed germination percentage showed that the seeds germination in Wadata was significantly higher $(\mathbf{P}<0.05)$ with $98.90 \%$ while Wurukum gave the least with $41.20 \%$. Aspergillus niger was found to be highest in NorthBank, Railway, Wadata and Wurukum markets with

\author{
Oyibe, U. \\ Department of Biological Sciences \\ Benue State University, Makurdi, Nigeria \\ Foga, J \\ Department of Biological Sciences \\ Benue State University, Makurdi, Nigeria
}

63.80, 53.30, 57.90 and $44.40 \%$ occurrence respectively. There was a significant $(P<0.05)$ inhibitory effect of Moringa seed extract on radial mycelia fungal growth, as the concentration increased, the radial growth decreased with $50 \%$ w/v giving the highest inhibitory effect. Thus it is conclude that some fungal are associated with seeds of soybean and treatment with Moringa seed extract showed that they can be used as plant base control agents for reducing seedborne fungal infection. Therefore the government should establish industry for formulation of these extracts and used in coating seeds prior to germination to increased productivity.

Keyword- Fungi, Incidence, radial growth, seed extract

\section{INTRODUCTION}

Soybean (Glycine max) is a species of Legumes native to East Asia, widely grown for its edible bean which has numerous uses. Soybean belongs to the family Fabaceae and the species name Glycine max, Soybean is popularly known as a "miracle bean" or a "golden bean" because it is an alternative cheap source of protein. Soybean is very nutritious especially useful for diabetics and is considered to be the richest vegetable food and also makes a good soup. Soybean milk is considered a good substitute for cow's milk and is quite suitable for children and is much cheaper too as compare to cow's milk. Casein and curd produced from this milk is of superior quality [1]. Soybean accounts for $72 \%$ production area of 198.7 million hectares of land cultivated for other crops such as groundnuts, pea, cowpea, pigeon pea and chickpea. Soybean have high 
protein content up to $36 \%$ and fat $20 \%$ making up $56 \%$ oil, soybean also contain $30 \%$ carbohydrate, $9 \%$ water and $5 \%$ ash. The attack by seed borne fungi on soybean during storage is one of the major problems affecting productivity of soybean, hence affecting the quality and shelf life of the seeds [2]. The use of chemical has been employed as one of the effective strategy to control these pathogens, but the residuals of these chemicals have adverse effect on the consumers as a result of their accumulation in food, on soil and washed off in water which is also consumed by humans. Therefore, the use of botanicals which are term generally recognized as safe (GRAS) are suggested alternatives to synthetic fungicides by various researchers [3]. Thus, the aim of this research is to investigate the occurrence and the control of seed borne fungi of soybean using plant extract.

\section{MATERIALS AND METHOD}

\section{A. Study Area}

The Experiment was carried out in Botany laboratory of the Department of Biological Science, Benue State University Makurdi, Nigeria. Makurdi is located on latitudes $7^{\circ} 30^{\circ} \mathrm{N}$ and $70^{\circ} 45^{\circ} \mathrm{N}$, longitudes $8^{\circ} 30^{\circ} \mathrm{E}$ and $8^{\circ} 35^{\circ} \mathrm{E}$ of the equator. The metropolis lies within the Benue valley in the middle belt zone of Nigeria, and it is divided by the Benue River into the North and South banks. The vegetation is evergreen all year round for grazing animals and farming activities which include the cultivation of crops like soybeans, maize, spinach, tobacco etc.

\section{B. Sample collection}

Soybean seeds samples were collected from four different markets in Makurdi, Nigeria. The markets were Wurukumt, North Bank, Wadata, and Railway markets. Thirty (30) seeds of soybean sample were collected from three different sale points in each market, making a total of 90 seeds per market and 360 seeds across all the four markets. The collected seeds were packaged in polythene bags, labeled properly and taken to the Botany laboratory of the Department of Biological Sciences, Benue State University, Makurdi for further analysis.

\section{Preparation of Media}

Potato Dextrose Agar (PDA) was used for the isolation of fungi from maize seeds. The medium was prepared from commercially produced dehydrated medium following the manufacturer's instruction. Thirty nine (39) grams of dehydrated PDA was dissolved in 1 litre of distilled water in a sterile conical flask and covered with cotton wool and aluminum foil paper. This was heated using heating mantle to dissolve the medium completely for a few minutes. The agar was afterwards autoclaved at $121^{\circ} \mathrm{C}$ for 15 minutes at $760 \mathrm{mmHg}$. The media was allowed to cool to temperature at which it can be held with hands. Two drops of Streptomycin sulphate powder was added to suppress bacterial contaminations. The PDA was poured aseptically by flame sterilizing the mouth and dispensed into $20 \mathrm{ml}$ Petri-dishes and was allowed to solidify.

\section{Assessment of the occurrence of fungi species and seed germination of Soybean samples Collected From different Markets in Makurdi.}

Blotter method of fungal detection and isolation.

Detection of seed-borne Fungi was done by standard blotter method as highlighted according to [4]. The seeds were surface sterilized in 5\% Sodium hypochlorite to remove external surface contaminants and rinsed in two changes of sterile distilled water to remove residual sodium hypochlorite. Three layers of Whatman filter paper was soaked in water and placed at the bottom of $9 \mathrm{~cm}$ diameter Petri dishes. Ten surface sterilized seeds were placed onto the soaked filter paper in Petri plates, labeled accordingly and then incubated at ambient condition of temperature and light for seven days. The seeds were watered everyday for seven days. The data collected include percentage fungi occurrence and percentage seed germination. On appearance of fungal growth after 7 days of incubation, a little quantity of each fungi colony was picked using inoculation needle and inoculated on prepared PDA. The Petri plates was incubated at ambient temperature for 3-4 days and observed daily for fungal growth. After 3-4 days, sub-culturing was done to obtain pure culture of the isolates. To subculture, a sterilized inoculation needle was used to pick a little quantity of the fungal growth on the old culture and transferred to a freshly prepared PDA in other Petri dishes. Sub-culturing was done two times until pure culture of each fungal organism was obtained.

Percentage occurrence of fungi and seed germination

Seeds were observed for growth and the total number of seeds with fungi growth was recorded and percentage occurrence of fungi was calculated using the formula adopted by [5]. 


\section{International Journal of Engineering Applied Sciences and Technology, 2020 Vol. 5, Issue 1, ISSN No. 2455-2143, Pages 606-611 \\ Published Online May 2020 in IJEAST (http://www.ijeast.com)}

Percentage occurrence of fungi

$=\frac{\text { Nunmber of times each fungus occurred }}{\text { Total number of fungi per plate }} \times 100$

Percentage seed germination

$=\frac{\text { Nunmber of seeds with seed leaf }}{\text { Total number of seeds per plate }} \times 100$

\section{Identification of fungi}

The identification of the isolates was done by examining the isolates macroscopically and microscopically. The colony characteristics such as colony appearance, change in medium colour and growth rate were observed on plates. Shapes of the conidia and conidiophores were taken note of under the microscope. These structural features were matched with standards text of [6].

\section{E. Preparation and Concentration of Moringa extract}

Seeds of Moringa (Moringa oleifera) were collected and different weight of $10 \mathrm{~g}, 20 \mathrm{~g}, 30 \mathrm{~g}, 40 \mathrm{~g}$ and $50 \mathrm{~g}$ were measured using electronic weighing scale. The seeds were surface sterilized with $1 \%$ sodium hypochlorite and rinsed in three changes of distilled water to remove residual sodium hypochlorite. Using a ceramic laboratory mortar and pestle, the weighed seeds were pounded separately and transferred into beakers. To obtain extract concentrations, $100 \mathrm{ml}$ of sterile distilled water was added to the macerated $10 \mathrm{~g}$ of Moringa seeds in the beaker to obtain $10 \% \mathrm{w} / \mathrm{v}$. The extract was allowed to stay for 3 hours and sieved with sieve cloth to obtain clear filtrate. The same procedure was followed to get concentrations of $20 \% \mathrm{w} / \mathrm{v}, 30 \% \mathrm{w} / \mathrm{v}, 40 \% \mathrm{w} / \mathrm{v}$, and $50 \% \mathrm{w} / \mathrm{v}$.

\section{F. Effect of Moringa Seed Extract on Mycelia Growth of Fungi In vitro}

The pour plate method was used to investigate the efficacy of the extracts on the test fungi in vitro. Two milliliters each 10\% w/v, 20\% w/v, 30\% w/v, 40\% $\mathrm{w} / \mathrm{v}$ and $50 \% \mathrm{w} / \mathrm{v}$ of the extract was dispensed in sterile Petri dishes after which $20 \mathrm{mls}$ of molten Potato Dextrose Agar (PDA) was added. The mixtures in the Petri dishes were swirled gently on the work bench to give an even dispersion of extracts. The agar extract mixture was allowed to solidify and then used for inhibition of mycelia growth of the test fungi. The medium was inoculated centrally with $4 \mathrm{~mm}$ diameter of mycelia discount obtained from the colony edge of 5-7 days old cultures of test fungi with the aid of inoculation needle. Three replications were used for each extract concentration for each test fungi. Controls were Petri dishes containing PDA with no botanical extract, inoculated with the test fungi. The plates were arranged on laboratory desk in a completely randomized design (CRD). The Petri plates were incubated at room temperature and measurement of the radial growth of fungi colony was done using a transparent metre rule on day 3,5 and 7 and recorded respectively. Fungal growth inhibition was determined using the formula below:

$$
\text { Growth inhibition of fungi }=\frac{R_{1}-R_{2}}{R_{1}} \times 100
$$

Where, $R_{1}=$ radial growth of fungi in control

$$
\mathrm{R}_{2}=\text { radial growth of fungi in treatment }
$$

\section{G. Experimental Design}

The experiment was a $1 \times 3 \times 6$ Factorial in Completely Randomized Design (CRD) replicated three (3) times. The treatment consist of one plant extract, namely Moringa seed, Six concentration of 0, 10, 20, 30,40 and $50 \% \mathrm{w} / \mathrm{v}$ and Three fungal isolates

\section{H. Effect of seed treatment with Moringa} Seed extract on the occurrence of seedborne fungi in Soybean

The plant extract was prepared and each concentration obtained as described earlier. Seeds from the market with the highest percentage occurrence of seed borne fungi were soaked in different concentrations of the plant extracts for 3 hours, removed from the solution and allowed to air dry. The treated seeds were plated using the blotter method earlier described. The Petri plates were incubated at ambient temperature. The percentage occurrence of fungi and germination rate was recorded seven (7) days after incubation. The formula earlier stated was used to determine percentage occurrence of fungi and seed germination respectively.

\section{Data Analysis}

The data collected was analyzed using Analysis of Variance and treatment means were separated using Fischer's Least Significant Difference at 5\% level of probability.

\section{RESULTS AND DISCUSSION}

The fungi organisms associated with Soybean seeds obtained from markets in Makurdi from this research were identified to be; Aspergillus niger, Aspergillus flavus and Rhizopus stolonifer. A. niger has a colony colour of dark brown to black while growing on PDA 
(Plate 1a) and microscopically, the conidiophores were hyaline, inflated at apex forming globose vesicles (Plate 1b). The colonies of $R$. stolonifer were fast growing with cotton to fluffy colouration on PDA (Plate 2a). The sporangiospores are hyaline, smooth walled, simple or branched forming large terminal globose (Plate 2b). The colony surface of $A$. flavus is greyish green in colour with moderate to rapid growth on PDA (Plate 3a). Conidia were light green in colour when viewed under the light microscope with long, hyaline and smooth conidiophores (Plate 3b).

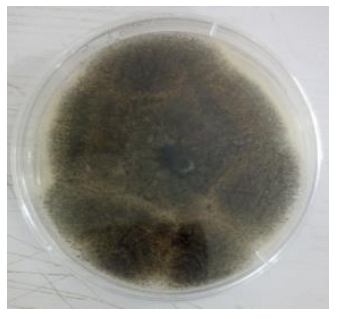

(a)

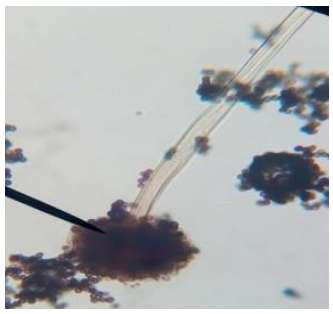

(b)
Plate 1. (a) A. niger on PDA (b) A. niger microscopy

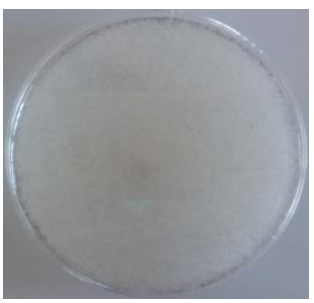

(a)

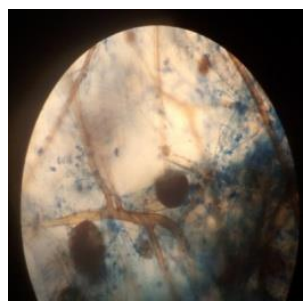

(b)
Plate 2 (a) R. stolonifer on PDA (b) R.stolonifer microscopy

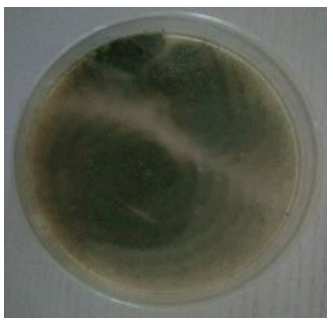

(a)

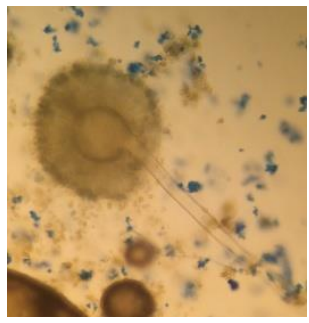

(b)
Plate 3 (a) A.flavus on PDA (b) A.flavus microscopy
The percentage occurrence and seed germination of seed borne fungi obtained in different markets in Makurdi is shown in Table 1. The result shows no significance difference ( $p>0.05$ ) in percentage occurrence of fungi in the different markets, although, there was high percentage occurrence. North Bank market has the highest occurrence with (84.40) and Railway market show the least occurrence with (58.90). The percentage seed germination was significantly higher $(\mathrm{P}<0.05)$ with Wadata recording the highest seed germination of (98.90) and the lowest found in Wurukum with (41.40)

Table 1: Percentage occurrence of fungi and seed germination across four different markets in Makurdi, Nigeria.

\begin{tabular}{|c|c|c|}
\hline Market & $\begin{array}{c}\text { \% fungi } \\
\text { occurrence }\end{array}$ & \% germination \\
\hline North Bank & 84.40 & 87.00 \\
\hline Railway & 58.90 & 58.90 \\
\hline Wadata & 63.30 & 98.90 \\
\hline Wurukum & 65.60 & 41.20 \\
\hline LSD & NS & 21.58 \\
\hline
\end{tabular}

Key: Ns: Not significant

Table 2 shows percentage occurrence of different fungal associated with sample of soybean seed collected. The occurrence of $R$. stolonifer was significantly higher in Wurukum with (38.50) and least occurrence in Wadata with (0.00). There was no significant difference in A.niger occurrence across the different markets while occurrence of A.flavus was significantly lower with (0.00) compared with Wadata recording the highest occurrence with (42.10).

Table 2: Percentage occurrence of different fungi isolates across different markets in Makurdi, Nigeria

\begin{tabular}{|c|c|c|c|}
\hline Market & $\begin{array}{c}R . \\
\text { stolonifer }\end{array}$ & A. $\quad$ Niger & A. flavus \\
\hline $\begin{array}{l}\text { North } \\
\text { Bank }\end{array}$ & 36.30 & 63.80 & 0.00 \\
\hline Railway & 17.90 & 53.30 & 17.90 \\
\hline Wadata & 0.00 & 57.90 & 42.10 \\
\hline Wurukum & 38.50 & 44.70 & 25.20 \\
\hline LSD(0.05) & 17.45 & NS & 14.62 \\
\hline
\end{tabular}

The antifungal effect of Moringa seed extract on mycelia growth of fungi isolates at day 3, 5 and 7 is displayed in Table 3. At day 3,5 and 7 radial growth in control was significantly higher $(\mathrm{P}<0.05)$ compared with the treated plates at different concentrations. In the treated plates radial growth decreased as concentration increased with $50 \% \mathrm{w} / \mathrm{v}$ giving the lowest radial growth. 
International Journal of Engineering Applied Sciences and Technology, 2020

Vol. 5, Issue 1, ISSN No. 2455-2143, Pages 606-611

Published Online May 2020 in IJEAST (http://www.ijeast.com)

Table3: Effect of Moringa seed extract on the radial growth of fungi isolated from soybean seeds

\begin{tabular}{|c|c|c|c|c|c|c|c|c|}
\hline \multicolumn{9}{|c|}{ 3 DAI } \\
\hline
\end{tabular}

Percentage of fungi occurrence and seed germination of Soybean seeds from North Bank, the location with the highest fungi occurrence treated with Moringa seed extract is shown in Table 4. The result shows there is significance higher $(\mathrm{p}<0.05)$ percentage occurrence of fungi and seed germination in the control compared with the treated seeds. The percentage fungi occurrence and seed germination decreased as concentration increased.

Table 4: Effect of Moringa seed concentration on percentage occurrence of seed borne-fungi and seed germination of soybean seed.

\begin{tabular}{|c|c|c|}
\hline $\begin{array}{c}\text { Concentration } \\
(\% \mathbf{w} / \mathbf{v})\end{array}$ & $\begin{array}{c}\text { \% occurrence of } \\
\text { fungi }\end{array}$ & \% seed germination \\
\hline 0 & 81.40 & 97.40 \\
\hline 10 & 44.40 & 94.40 \\
\hline 20 & 35.60 & 90.70 \\
\hline 30 & 30.00 & 77.80 \\
\hline 40 & 31.10 & 84.40 \\
\hline 50 & 28.90 & 81.10 \\
\hline LSD $(0.05)$ & 7.69 & 10.77 \\
\hline
\end{tabular}

Seed borne fungi associated with soybean in this research were identified as; Aspergillus niger,
Aspergillus flavus and Rhizopus stolonifer. A similar study was carried out by $[7,8,9]$. There is a high percentage occurrence of fungi infected soybean seeds in this work which could be as a result of moisture content of the seeds from post harvest drying and also environmental conditions of the market. The materials used in conveying the seeds from the area they were cultivated to the markets could also explain the high level of fungi occurrence. Fungi are ubiquitous in nature and their spores can be dispersed easily through air thus the contact of these seeds or their proximity with other infected seeds also provide another explanation to high fungi occurrence. North Bank market with the highest percentage occurrence of fungi is an area with poor hygienic practices and also close to the river bank which provide a medium for fungi growth. Effect of Moringa seed extract on radial growth of fungi was tested, the extracts prove to be effective in the inhibition of fungi growth especially at higher concentrations. Inhibition of fungi growth by Moringa extract could be as a result of phytochemicals present in the plant and its accumulation in higher concentration could explain while higher concentration gave the best inhibitory effect. This was similar to related studies by $[8,10,11]$ who reported that the phytochemicals present in plants account for their antifungal potentials. The decrease effect in the germination of soybean seeds treated with Moringa seed extract could be as a result that, there might be a compound in the extract reacting with oxygen there by absorbing the oxygen 
needed by the seed for germination, or this might be as a result of lethal effect of the extract on water inhibition rate of the seeds. Therefore, in trying to disinfect seed completely might have effect on plant germination and performance, this result is similar with the findings of [12].

\section{CONCLUSION AND ACKNOWLEDGEMENT}

The findings from this study implicated Rhizopus stolonifer, Aspergillus niger and aspergillus flavus as pathogenic fungi associated with soybean seed in Makurdi, Nigeria. Moringa seed extract can be used to control pathogenic fungi associated with soybean seeds since all the concentration shows good percentage of inhibition, though $50 \% \mathrm{w} / \mathrm{v}$ have the highest inhibition and seed treated with the extract also show reduction in fungi occurrence. Thus Moringa seed extract formulation can be used as alternatives to synthetic fungicides in maintaining good seeds as they are eco friendly and are non toxic for human consumption.

Our sincere appreciation goes to the Department of the Biological Sciences for granting permission to use the Botany Laboratory and equipment for carrying out this research.

\section{REFERENCES}

[1] .Afolabi, Q. O. and Kareem, K. T. (2018). Antifungal activities of Carica papaya and Sodium bircarbonate against soybean fungi. International journal of biological and chemical sciences, (pp. 2085-2092).

[2] Talba, U. and Zakari, B. G. (2017). Identification and control of seed borne-fungi pathogens of Maize using plants extracts. International journal of science and research, 10.21275/ART20183363

[3]. Tewai, B.B., Subramania, G. and Gomalhinayagm, R. (2014). Antimicrobial properties of Carica papaya different leaf extract against $E$. coli, $S$. aureus and $C$. albicans. American journal of pharmercology and pharmercotherapeutic, (pp. 35-42).

[4]. Ekefan, E. J., Nwankiti, A. O. and Gwa, V.I. (2018). Comparative Assessment of Antimicrobial potency of some selected plants extracts against seed borne pathogens of germinating yam sets. Journal of plant pathology and microbiology, 10.4172/2157-7471-1000444.
[5]. Liamngee, K., Aondo-Terkaa, O. and Akinyemi, B.K. (2016). Isolation and identification of seed borne fungi of common bean (Phaseolus vulgaris L.) from selected markets in Makurdi”. International Journal of Applied Agricultural Sciences, (pp. 75-78).

[6]. Barnett, H.L. and Hunter, B.B. (1972). Illustrated Genera of Imperfect fungi $3^{\text {rd }}$ edition Burgess, Minnesota, pp. 273

[7]. Makun, A.H., Anjorin, S.T., Rufai, A.S. and Kabiru, Y.A. (2012). Incidence and Botanical control of seed borne fungi of cowpea in Niger State, Nigeria. APRN Journal of Agricultural and Biological Sciences, (pp. 654-658).

[8]. Suleiman, M.N. and Omafe, O.M. (2014). Activity of three medicinal plants on fungi isolated from stored maize seeds (Zea mays L.). FUTA Journal of Research in Sciences, (pp. 276-281).

[9]. Sreenu, B. A., Girish, G., Alice, J. and Sujeetha, R.P. (2019). Identification and detection of maize seeds pathogens using different seed testing methods. International Journal of Current Microbiology and Applied Sciences, 10.20546/ijcmas.2019.810.171.

[10].Suleiman, M.N. and Omafe, O.M. (2014). Activity of three medicinal plants on fungi isolated from stored maize seeds (Zea mays L.). FUTA Journal of Research in Sciences, (pp. 276-281)

[11].Zubbair, N.A. and Opabola, R.A. (2009). Effect of leaf extracts of Almond, Frangipani, Neem and Eucalyptus on growth of Fusarium moniliforme; A seed borne fungal pathogen of maize (Zea mais L.)". Journal of Interdisciplinary sciences and Technology, (pp. 79- 83).

[12]. Debnath, M. Sultana, A. and Rashid, A. Q. M. B (2012). Effect of seed-borne fungi on the germinating seeds and their Bio-control in Maize. Journal of environmental Science and natural resources, (pp. 117-120). 